Optimal Taxation in the Uzawa-Lucas Model with Externality in Human Capital 
Los documentos de trabajo del Ivie ofrecen un avance de los resultados de las investigaciones económicas en curso, con objeto de generar un proceso de discusión previo a su remisión a las revistas científicas. Al publicar este documento de trabajo, el Ivie no asume responsabilidad sobre su contenido.

Ivie working papers offer in advance the results of economic research under way in order to encourage a discussion process before sending them to scientific journals for their final publication. Ivie's decision to publish this working paper does not imply any responsibility for its content.

La Serie AD es continuadora de la labor iniciada por el Departamento de Fundamentos de Análisis Económico de la Universidad de Alicante en su colección "A DISCUSIÓN" y difunde trabajos de marcado contenido teórico. Esta serie es coordinada por Carmen Herrero.

The AD series, coordinated by Carmen Herrero, is a continuation of the work initiated by the Department of Economic Analysis of the Universidad de Alicante in its collection "A DISCUSIÓN", providing and distributing papers marked by their theoretical content.

Todos los documentos de trabajo están disponibles de forma gratuita en la web del Ivie http:/ / www.ivie.es, así como las instrucciones para los autores que desean publicar en nuestras series.

Working papers can be downloaded free of charge from the Ivie website http://www.ivie.es, as well as the instructions for authors who are interested in publishing in our series.

Edita / Published by: Instituto Valenciano de Investigaciones Económicas, S.A.

Depósito Legal / Legal Deposit no.: V-3398-2011

Impreso en España (septiembre 2011) / Printed in Spain (September 2011) 
WP-AD 2011-19

\title{
Optimal Taxation in the Uzawa-Lucas Model with Externality in Human Capital ${ }^{*}$
}

\author{
Arantza Gorostiaga, Jana Hromcová and \\ Miguel-Ángel López-García**
}

\begin{abstract}
We show that in the Uzawa-Lucas model with externality in human capital with agents that value both consumption and leisure, the government pursuing the first best can achieve its goal by subsidizing the foregone earnings while studying. The subsidy should be financed by a schooling fee. We obtain that countries with similar initial conditions may issue different fees because multiple equilibria can arise for empirically plausible values of parameters. This result differs from the one obtained in ananalogous economy where agents only value consumption.
\end{abstract}

Keywords: optimal policy, two-sector model, endogenous growth, indeterminacy.

JEL codes: O41, E62, H31.

\footnotetext{
* Financial support from the Spanish Ministry of Education and Science through grants SEJ200760671/ECON (Hromcová), ECO2009-009732 (Gorostiaga), ECO2009-10003 (López-García), ECO201016353 (Hromcová), Generalitat de Catalunya through the Barcelona GSE research network (Hromcová) and SGR2009-0600 and XREPP (Hromcová and López-García), Basque Government grant IT-214-07 (Gorostiaga) and Instituto Valenciano de Investigaciones Económicas are gratefull y acknowledged.

** A. Gorostiaga, Universidad del País Vasco, Departamento de Fundamentos del Análisis Económico II; J. Hromcová a nd M.A. López-García, Universitat Autònoma de Barcelona, Departament d'Economia Aplicada. Corresponding author: J. Hromcová, jana.hromcova@uab.cat.
} 


\section{Introduction}

Human capital growth expands future possibilities. Hence the importance of its accumulation for the human development and economic growth. Building on Uzawa (1965) and Lucas (1988), a lot of research has been devoted to the study of the dynamics of two sector models with agents that have to decide on the optimal allocation of human capital across the production and education sectors. ${ }^{1}$

One of the most widely studied extensions of the Uzawa framework was introduced by Lucas (1988) and assumes human capital externalities in the production of goods: the average human capital stock increases total factor productivity, but this is not taken into account by individual agents when making economic decisions. It is a well known result that in such a model the competitive equilibrium does not coincide with the social optimum. In the absence of public intervention, time devoted to accumulate human capital and the growth rate at the steady state are too low. However, there may exist policies that allow to decentralize the first best outcome.

Several papers have addressed this question in theoretical setups where the utility is derived only from consumption. For example, Bethmann (2007) develops a closed form solution and shows that the optimal allocation is reached by taxing labor income and subsidizing capital income. García-Castrillo and Sanso (2000) prove that the first best could be reached under a direct subsidy of the time devoted to education funded through a lump-sum tax and a tax on human capital income. In a similar model, Gómez (2003) shows that lump sum taxation can be avoided and that the optimal solution can be achieved by taxing labor income and subsidizing the investment into human capital.

In this paper we extend the model economy in Gómez (2003) with agents that value both consumption and leisure. Our analysis considers subsidies that depend on foregone income while studying which might be funded with revenues obtained by taxing labor and capital incomes, and through lump sum taxes. We show that when agents face labor-leisure choice, the combinations of taxes and subsidies that decentralize the social optimum are different from the ones discussed above. In particular, lump sum taxation has to be included in the design of the optimal policy and labor and capital income taxes should be set equal to zero. We perform our analysis in a representative agent infinite horizon model with general utility and production functions. Nevertheless, a discrete version of the model allows us to present an analytical solution for a certain combination

\footnotetext{
${ }^{1}$ Just to mention for example Caballé and Santos (1993), Chamley (1993), Mulligan and Sala-i-Martin (1993), Benhabib and Perli (1994), García-Castrillo and Sanso (2000), Ben-Gad (2003), Gómez (2003), Gómez (2004), Bethmann (2007), among many others.
} 
of functional forms for the utility and production technology.

Finally, some papers in this literature have studied the model assumptions under which the balanced growth path is unique and fully determined. Benhabib and Perli (1994) discuss the multiplicity of equilibria and transitional paths in the Uzawa-Lucas model with externality in human capital. They show that if the externality is high, there always exists a continuum of equilibria. Under some conditions the balanced growth path can become indeterminate, too. Ladrón-de-Guevara et al. (1997 and 1999) consider a model without externalities and show that by including leisure in the utility function multiple balanced growth paths arise. The fact that indeterminacy may arise in our setup implies that two different economies that face similar initial conditions may choose different optimal allocations for working, leisure time and consumption. Therefore, optimal subsidies to foregone earnings and schooling fees may differ in these economies.

The remainder of the paper is organized as follows. The model and its main properties for the competitive and social planner equilibria are stated in section 2 . The optimal policy in derived in section 3. Final conclusions are summarized in section 4.

\section{The Model Economy}

We consider a model economy that extends Uzawa (1965) and Lucas (1988) to include leisure-labor decisions. There are two production sectors: the final good sector and the education sector that produces new human capital. The economy is populated by identical and infinitely lived agents. Total population is assumed to be constant and normalized to one. Households have initial endowments of physical and human capital, $k_{0}$ and $h_{0}$, respectively. Agents also have an endowment of one unit of time at each period $t$ that they allocate to the production of the final good, $u_{t}$, leisure activities, $l_{t}$, or human capital accumulation, $1-u_{t}-l_{t}$.

\subsection{Final Good Sector}

The final good sector produces a commodity that can be consumed or accumulated as physical capital. The technology in this sector combines physical capital, $k_{t}$, and efficiency units of labor, $L_{t}=u_{t} h_{t}$, and is described through the following production function

$$
y_{t}=h_{a_{t}}^{\gamma} F\left(k_{t}, u_{t} h_{t}\right)
$$

where $h_{a_{t}}$ is the average human capital stock and the term $h_{a_{t}}^{\gamma}$ captures the external effect of average human capital in the production of goods. Finally, $F\left(k_{t}, L_{t}\right)$ is 
homogeneous of degree one, concave, increasing and such that $\lim _{k_{t} \rightarrow 0} F_{k}\left(k_{t}, L_{t}\right)=0$, $\lim _{L_{t} \rightarrow 0} F_{L}\left(k_{t}, L_{t}\right)=0$, and $F\left(0, L_{t}\right)=F\left(k_{t}, 0\right)=0$. Note that parameter $\gamma$ measures the degree of the externality and also the degree of increasing returns to scale at the social level.

Firms maximize profits taking prices and the average stock of human capital as given. Inputs' demands are such that

$$
r_{t}+\delta_{k}=F_{k}\left(k_{t}, u_{t} h_{t}\right) h_{a_{t}}^{\gamma}
$$

and

$$
w_{t}=F_{L}\left(k_{t}, u_{t} h_{t}\right) h_{a_{t}}^{\gamma}
$$

where $r_{t}$ is the return on capital, $\delta_{k}$ is the rate at which the physical capital depreciates and $w_{t}$ is the wage per efficiency unit of labor.

\subsection{Education Sector}

The schooling sector produces human capital services. Human capital accumulation depends on the time spent studying $1-u_{t}-l_{t}$ and on the level of human capital $h_{t}$ according to

$$
h_{t+1}=\phi\left(1-u_{t}-l_{t}\right) h_{t}+\left(1-\delta_{h}\right) h_{t}
$$

where $\phi$ is a measure of productivity in the education sector and $\delta_{h}$ is the depreciation rate of human capital.

\subsection{Households}

Households derive utility from consumption, $c_{t}$, and leisure, $l_{t}$. Lifetime welfare is characterized by the utility function

$$
\sum_{t=0}^{\infty} \beta^{t} U\left(c_{t}, l_{t}\right)
$$

where $\beta$ is the discount factor. The function $U(\cdot, \cdot)$ is increasing, strictly concave, twice continuously differentiable and additively separable in both arguments.

Households pay proportional labor income taxes at rate $\tau_{w_{t}}$ and capital income taxes at rate $\tau_{r_{t}}$. The government subsidizes the investment in human capital funding a fraction $s_{t}$ of wage income that is foregone while studying. Finally, the model also considers a lump sum tax or subsidy $\mathbb{T}_{t}$. The budget constraint that agents face at $t$ can be written as

$$
c_{t}+k_{t+1}-k_{t} \leq\left(1-\tau_{r_{t}}\right) r_{t} k_{t}+\left(1-\tau_{w_{t}}\right) w_{t} h_{t} u_{t}-\mathbb{T}_{t}+s_{t} w_{t}\left(1-u_{t}-l_{t}\right) h_{t}
$$


The problem of the representative agent is to maximize the lifetime utility (5), subject to the budget constraint (6), and the condition for the accumulation of human capital (4) and taking as given prices, policies and initial values for physical and human capital. Let $\lambda_{t}$ and $\varepsilon_{t}$ be the non-negative Lagrange multipliers associated with the budget constraint (6) and the condition for the accumulation of human capital (4), respectively. The first order necessary conditions on consumption, labor, leisure, physical and human capital, respectively, are

$$
\begin{aligned}
U_{c}\left(c_{t}, l_{t}\right) & =\lambda_{t} \\
\lambda_{t}\left(1-\tau_{w_{t}}-s_{t}\right) w_{t} h_{t}= & \phi \varepsilon_{t} h_{t} \\
U_{l}\left(c_{t}, l_{t}\right)= & \lambda_{t} s_{t} w_{t} h_{t}+\phi \varepsilon_{t} h_{t} \\
\lambda_{t}= & \beta \lambda_{t+1}\left[\left(1-\tau_{r_{t+1}}\right) r_{t+1}+1\right] \\
\varepsilon_{t}= & \beta \lambda_{t+1}\left[\left(1-\tau_{w_{t+1}}\right) w_{t+1} u_{t+1}+s_{t+1} w_{t+1}\left(1-u_{t+1}-l_{t+1}\right)\right] \\
& +\beta \varepsilon_{t+1}\left\{\phi\left(1-u_{t+1}-l_{t+1}\right)+1-\delta_{h}\right\}
\end{aligned}
$$

and transversality conditions

$$
\begin{aligned}
& \lim _{t \rightarrow \infty} \beta^{t} \lambda_{t} k_{t+1}=0, \\
& \lim _{t \rightarrow \infty} \beta^{t} \varepsilon_{t} h_{t+1}=0 .
\end{aligned}
$$

The Lagrange multipliers associated with the budget constraint and the constraint on human capital accumulation, $\lambda_{t}$ and $\varepsilon_{t}$, can be interpreted as the marginal utility of wealth and the shadow price of human capital, respectively. The first order condition on consumption (7) indicates the marginal utility of wealth. The first order conditions on working and leisure time, (8) and (9), determine the optimal allocation of time among the three activities, working, studying and leisure. The first order conditions on physical capital (10) and human capital (11) embody the costs and profits associated with investing one marginal unit of wealth in either capital.

Plugging (7) and (8) into (9) and (10), we can easily get the usual intertemporal and 
intratemporal first order conditions

$$
\begin{aligned}
& U_{c}\left(c_{t}, l_{t}\right)=\beta U_{c}\left(c_{t+1}, l_{t+1}\right)\left[1+\left(1-\tau_{r_{t+1}}\right) r_{t+1}\right] \\
& U_{l}\left(c_{t}, l_{t}\right)=U_{c}\left(c_{t}, l_{t}\right)\left(1-\tau_{w_{t}}\right) w_{t} h_{t} .
\end{aligned}
$$

Note that the capital income tax distorts intertemporal consumption decisions and the labor income tax distorts consumption-leisure decisions.

\subsection{Government}

Fiscal policy targets human capital accumulation. The government taxes capital and labor income and subsidizes the investment in human capital. Wages lost while studying are subsidized by a flat rate. Any missing (remaining) income is taken from (transferred back to) the consumers in the form of lump-sum tax (subsidy) in order to keep the government's budget constraint balanced at every moment

$$
\tau_{r_{t}} r_{t} k_{t}+\tau_{w_{t}} w_{t} h_{t} u_{t}+\mathbb{T}_{t}=s_{t} w_{t}\left(1-u_{t}-l_{t}\right) h_{t}
$$

\subsection{Competitive Equilibrium}

Definition: Given initial conditions $h_{0}$ and $k_{0}$ and a tax policy $\left\{\tau_{r_{t}}, \tau_{w_{t}}, s_{t}\right\}_{t=0}^{\infty}$, allocations $\left\{c_{t}^{C E}, k_{t+1}^{C E}, l_{t}^{C E}, u_{t}^{C E}, h_{t+1}^{C E}, h_{a_{t}}^{C E}, y_{t}^{C E}\right\}_{t=0}^{\infty}$, lump sum transfers $\left\{\mathbb{T}_{t}^{C E}\right\}_{t=0}^{\infty}$ and prices $\left\{r_{t}^{C E}, w_{t}^{C E}\right\}_{t=0}^{\infty}$ constitute a competitive equilibrium if the following conditions are satisfied:

(i) Given prices $\left\{r_{t}^{C E}, w_{t}^{C E}\right\}_{t=0}^{\infty}$ and policies $\left\{\tau_{r_{t}}, \tau_{w_{t}}, s_{t}, \mathbb{T}_{t}^{C E}\right\}_{t=0}^{\infty}$, allocations $\left\{c_{t}^{C E}, k_{t}^{C E}, l_{t}^{C E}, u_{t}^{C E}, h_{t}^{C E}, y_{t}^{C E}\right\}_{t=0}^{\infty}$ solve the household's problem.

(ii) Given prices $\left\{r_{t}^{C E}, w_{t}^{C E}\right\}_{t=0}^{\infty}$ and the average human capital $\left\{h_{a_{t}}^{C E}\right\}_{t=1}^{\infty}$, allocations $\left\{k_{t}^{C E}, u_{t}^{C E} h_{t}^{C E}\right\}_{t=0}^{\infty}$ solve the firm problem.

(iii) The average human capital $h_{a_{t}}^{C E}$ is equal to $h_{t}^{C E}$ at each period $t$.

(iv) The government budget is balanced in every period.

(v) All markets clear. 
Therefore, when we consider a decentralized economy, equilibrium allocations, prices and policies have to satisfy equation (4) and equations (6) to (13) from the household problem, equations (1) to (3) from the firm's problem, the government budget constraint (16) and an additional expression equating $h_{t}$ and $h_{a_{t}}$.

\subsection{Social Planner Problem}

In this section we present the centralized economy. We assume that a social planner who internalizes the externality of human capital allocates resources and time so as to maximize lifetime utility. There will be two constraints in the planner's problem: one characterizing the human capital production technology, equation (4), and the so called resource constraint,

$$
c_{t}+k_{t+1}-\left(1-\delta_{k}\right) k_{t} \leq h_{t}^{\gamma} F\left(k_{t}, u_{t} h_{t}\right) \text {. }
$$

The necessary conditions for the first best allocation $\left\{c_{t}^{S P}, k_{t}^{S P}, l_{t}^{S P}, u_{t}^{S P}, h_{t}^{S P}\right\}$ are the transversality conditions, equations (12) and (13), and the following set of equations

$$
\begin{aligned}
U_{c}\left(c_{t}^{S P}, l_{t}^{S P}\right)= & \lambda_{t}^{S P}, \\
\lambda_{t}^{S P} h_{t}^{S P \gamma+1} F_{L}\left(k_{t}^{S P}, u_{t}^{S P} h_{t}^{S P}\right)= & \phi \varepsilon_{t}^{S P} h_{t}^{S P}, \\
U_{l}\left(c_{t}^{S P}, l_{t}^{S P}\right)= & \phi \varepsilon_{t}^{S P} h_{t}^{S P}, \\
\lambda_{t}^{S P}= & \beta \lambda_{t+1}^{S P}\left[h_{t+1}^{S P \gamma} F_{k}\left(k_{t+1}^{S P}, u_{t+1}^{S P} h_{t+1}^{S P}\right)+1-\delta_{k}\right] \\
\varepsilon_{t}^{S P}= & \beta \lambda_{t+1}^{S P}\left[\gamma h_{t+1}^{S P \gamma-1} F\left(k_{t+1}^{S P}, u_{t+1}^{S P} h_{t+1}^{S P}\right)+h_{t+1}^{S P \gamma} u_{t+1}^{S P} F_{L}\left(k_{t+1}^{S P}, u_{t+1}^{S P} h_{t+1}^{S P}\right)\right]+ \\
& +\beta \varepsilon_{t+1}^{S P}\left\{\phi\left(1-u_{t+1}^{S P}-l_{t+1}^{S P}\right)+1-\delta_{h}\right\} .
\end{aligned}
$$

Since the planner takes into account the impact of average human capital in the production technology, she will find optimal to devote more time to schooling than in a competitive equilibrium with no public intervention.

As in the competitive equilibrium case, we can substitute first order conditions (18) and (19) into equations (20) and (21) to get the intertemporal and intratemporal first 
order conditions of the planner's problem

$$
\begin{aligned}
& U_{c}\left(c_{t}^{S P}, l_{t}^{S P}\right)=\beta U_{c}\left(c_{t+1}^{S P}, l_{t+1}^{S P}\right)\left[1+h_{t+1}^{S P} \gamma F_{k}\left(k_{t+1}^{S P}, u_{t+1}^{S P} h_{t+1}^{S P}\right)-\delta_{k}\right], \\
& U_{l}\left(c_{t}^{S P}, l_{t}^{S P}\right)=U_{c}\left(c_{t}^{S P}, l_{t}^{S P}\right) h_{t}^{S P} \gamma+1 F_{L}\left(k_{t}^{S P}, u_{t}^{S P} h_{t}^{S P}\right) .
\end{aligned}
$$

The two equations above show that in the first best allocation, there is no wedge neither between the intertemporal marginal rate of substitution in consumption and the gross return on capital nor between the marginal rate of substitution between leisure and consumption and the marginal product of labor. As we will see in the next section, any policy designed to decentralize the first best should not lead to any wedge between marginal rates of substitution and marginal rates of transformation.

\subsection{Multiplicity of equilibria and policy}

Due to the aggregate increasing returns in the production technology and leisure in the utility, there might exist a unique path towards a unique balanced growth path, or arise a continuum of transition paths or multiple balanced growth paths for some sets of parameters, as discussed for example in Benhabib and Perli (1994) or Ladrón-de-Guevara et al. (1997). This means that the optimal education policy should react to the actual choice of consumption and time allocation between different activities at each moment of time. Two countries with similar initial conditions but different choices of endogenous variables might require different government action to reach the optimum.

\section{Optimal policy}

This section studies the fiscal policy that allows to decentralize the first best allocation, that is, the policy that will lead to a competitive equilibrium with allocations, prices and welfare as those chosen by the central planner. We prove that when households derive utility from leisure, lump sum taxation cannot be avoided in the design of the optimal policy.

We first study how to set taxes on capital and labor income to reach the first best outcome. The first proposition shows that both types of taxation should be left out of the optimal system. 
Proposition 1 The optimal fiscal policy that decentralizes the first best allocation should set capital income and labor income taxes equal to zero.

Proof. We build the optimal policy by comparing the system of equations that characterize a competitive equilibrium to the set that results from the planner's problem. The optimal tax policy is such that both systems imply the same constraints on the endogenous variables of the model. We prove that $\tau_{w_{t}}=\tau_{r_{t}}=0$ is a necessary condition for the optimal policy to implement the first best allocation by comparing the intratemporal and the intertemporal first order conditions in the competitive equilibrium and in the planner's problem solution. In a competitive equilibrium, equations (2)-(3) and (14)-(15) imply that

$$
\begin{aligned}
& U_{c}\left(c_{t}^{C E}, l_{t}^{C E}\right)=\beta U_{c}\left(c_{t+1}^{C E}, l_{t+1}^{C E}\right)\left\{1+\left(1-\tau_{r_{t+1}}\right)\left[h_{a_{t+1}}^{C E} F_{k}\left(k_{t+1}^{C E}, u_{t+1}^{C E} h_{t+1}^{C E}\right)-\delta_{k}\right]\right\} \\
& U_{l}\left(c_{t}^{C E}, l_{t}^{C E}\right)=U_{c}\left(c_{t}^{C E}, l_{t}^{C E}\right)\left(1-\tau_{w_{t}}\right) h_{t}^{C E}{ }^{\gamma+1} F_{L}\left(k_{t}^{C E}, u_{t}^{C E} h_{t}^{C E}\right)
\end{aligned}
$$

Setting both tax rates to zero, these two conditions become equal to (23) and (24).

The optimal policy implements the optimal wedge between marginal rates of substitution and marginal rates of transformation. Ruling out capital taxation results in a competitive equilibrium with undistorted intertemporal consumption/savings decisions as in the social planner outcome. On the other hand, labor income taxes increase the relative price of leisure and lead to a non-optimal allocation of consumption and leisure time. The first best can only be reached by setting distorting labor taxes equal to zero.

Proposition 1 discards capital and labor income taxes. Hence, if there were a subsidy policy to decentralize the first best, those subsidies should be funded through lump sum taxes. The following proposition characterizes the dynamics of the optimal subsidy policy and the funding by lump sum taxation.

Proposition 2 The first best allocation is decentralized through a policy consisting in subsidies that are proportional to foregone earnings while studying. The subsidy rate evolves according to

$$
\left(1-\delta_{h}\right) s_{t+1}=a_{t+1}^{S P} s_{t}-b_{t+1}^{S P}
$$

where

$$
a_{t+1}^{S P}=\frac{\phi \gamma F\left(k_{t+1}^{S P}, u_{t+1}^{S P} h_{t+1}^{S P}\right)}{h_{t+1}^{S P} F_{L}\left(k_{t+1}^{S P}, u_{t+1}^{S P} h_{t+1}^{S P}\right)}+\phi\left(1-l_{t+1}^{S P}\right)+1-\delta_{h}
$$


and

$$
b_{t+1}^{S P}=\frac{\phi \gamma F\left(k_{t+1}^{S P}, u_{t+1}^{S P} h_{t+1}^{S P}\right)}{h_{t+1}^{S P} F_{L}\left(k_{t+1}^{S P}, u_{t+1}^{S P} h_{t+1}^{S P}\right)} .
$$

Revenues to fund the subsidy are collected through lump sum taxes.

Proof. We follow the same strategy as in the previous proposition. We will compare the equilibrium conditions of the social planner's problem and the competitive equilibrium. Substituting (8) into (11) and using (9) we obtain the first order condition on human capital in terms of marginal utility of leisure. Substituting for wages and interest rates with the marginal productivity of labor and capital, (2) and (3), respectively, we can write

$$
\frac{1}{\beta} \frac{U_{l}\left(c_{t}^{C E}, l_{t}^{C E}\right)}{U_{l}\left(c_{t+1}^{C E}, l_{t+1}^{C E}\right)} \frac{h_{t+1}^{C E}}{h_{t}^{C E}}=\frac{\left(1-\tau_{w_{t}}\right)}{\left(1-\tau_{w_{t}}-s_{t}\right)}\left[\phi\left(1-l_{t+1}^{C E}\right)+\frac{\left(1-\tau_{w_{t+1}}-s_{t+1}\right)}{\left(1-\tau_{w_{t+1}}\right)}\left(1-\delta_{h}\right)\right]
$$

for the competitive solution. Analogously for the social planner problem, using (19), (20) and (22) we obtain

$$
\frac{1}{\beta} \frac{U_{l}\left(c_{t}^{S P}, l_{t}^{S P}\right)}{U_{l}\left(c_{t+1}^{S P}, l_{t+1}^{S P}\right)} \frac{h_{t+1}^{S P}}{h_{t}^{S P}}=\phi\left[\frac{\gamma F\left(k_{t+1}^{S P}, u_{t+1}^{S P} h_{t+1}^{S P}\right)}{h_{t+1}^{S P} F_{L}\left(k_{t+1}^{S P}, u_{t+1}^{S P} h_{t+1}^{S P}\right)}+1-l_{t+1}^{S P}\right]+1-\delta_{h} .
$$

Equations (30) and (31) are equivalent when

$$
\frac{\left(1-\tau_{w_{t}}\right)}{\left(1-\tau_{w_{t}}-s_{t}\right)}\left[\phi\left(1-l_{t+1}^{S P}\right)+\frac{\left(1-\tau_{w_{t+1}}-s_{t+1}\right)}{\left(1-\tau_{w_{t+1}}\right)}\left(1-\delta_{h}\right)\right]=\phi\left[\frac{\gamma F\left(k_{t+1}^{S P}, u_{t+1}^{S P} h_{t+1}^{S P}\right)}{h_{t+1}^{S P} F_{L}\left(k_{t+1}^{S P}, u_{t+1}^{S P} h_{t+1}^{S P}\right)}+1-l_{t+1}^{S P}\right]+1-\delta_{h} .
$$

Using the result from Proposition 1, setting the tax on labor income $\tau_{w_{t}}=\tau_{w_{t+1}}=0$, we obtain (27).

We can easily prove that the resource constraint (17) holds in a competitive equilibrium when the agent's budget constraint (6), the government budget constraint (16) and the firm's problem first order conditions (2)-(3) are satisfied. Finally, since all other taxes introduce distortions and are, therefore, left out of the optimal policy scheme, the funding of optimal subsidies should rely on lump sum taxes.

If we restrict the production function to a Cobb-Douglas functional form, we get a model economy for which the first best can be decentralized through subsidies that depend on time allocated to the production of goods and to leisure. These subsidies will be constant in the balanced growth path. The following proposition presents formally the characterization of the optimal policy for this production function.

Proposition 3 When we assume a Cobb-Douglas functional form for the production technology, i.e. $F\left(k_{t}, u_{t} h_{t}\right)=A k_{t}^{\alpha}\left(u_{t} h_{t}\right)^{1-\alpha}$, where $A$ is the technology parameter and 
$0<\alpha<1$ is the share of physical capital in output, the law of motion of the optimal subsidy rate is given in (27) where

$$
a_{t+1}^{S P}=\frac{\phi \gamma u_{t+1}^{S P}}{(1-\alpha)}+\phi\left(1-l_{t+1}^{S P}\right)+1-\delta_{h}
$$

and

$$
b_{t+1}^{S P}=\frac{\phi \gamma u_{t+1}^{S P}}{(1-\alpha)}
$$

Moreover, for the family of functional forms for the utility function consistent with a balanced growth path, the optimal subsidy rate converges in the long run to

$$
s^{*}=\frac{\gamma u^{S P^{*}}}{\gamma u^{S P^{*}}+(1-\alpha)\left(1-l^{S P^{*}}\right)} .
$$

where $u^{S P *}$ and $l^{S P *}$ are time allocated to work and leisure in the balanced growth path, respectively.

Proof. Under a Cobb-Douglas production function $\frac{\gamma F\left(k_{t+1}, u_{t+1} h_{t+1}\right)}{h_{t+1} F_{L}\left(k_{t+1}, u_{t+1} h_{t+1}\right)}=\frac{\gamma u_{t+1}}{1-\alpha}$. Substituting into (28) and (29) we get (32) and (33). On a balanced growth path the fraction of the time endowment devoted to work and leisure activities remain constant, $u_{t}=u_{t+1}=u^{*}$ and $l_{t}=l_{t+1}=l^{*}$. The subsidy that implements the first best is also constant. So when $s_{t}=s_{t+1}=s^{*}$ for any period $t,(27)$ implies (34).

Note that the series $\left\{u_{t+1}^{S P}, l_{t+1}^{S P}, k_{t+1}^{S P}, h_{t+1}^{S P}\right\}_{t=0}^{\infty}$ necessary to compute $a_{t+1}^{S P}$ and $b_{t+1}^{S P}$ in the dynamic equation (27) are given by the solution to the social planner problem. For a particular case of $\delta_{h}=1$ equation (27) implies

$$
s_{t}=\frac{b_{t+1}^{S P}}{a_{t+1}^{S P}}
$$

For a more general case of $0 \leq \delta_{h}<1$ substituting recursively into (27) we get

$$
s_{t+1}=s_{0} \frac{a_{1}^{S P}}{1-\delta_{h}} \frac{a_{2}^{S P}}{1-\delta_{h}} \ldots \frac{a_{t+1}^{S P}}{1-\delta_{h}}+\frac{b_{1}^{S P}}{1-\delta_{h}} \frac{a_{2}^{S P}}{1-\delta_{h}} \ldots \frac{a_{t+1}^{S P}}{1-\delta_{h}}+\ldots+\frac{b_{t}^{S P}}{1-\delta_{h}} \frac{a_{t+1}^{S P}}{1-\delta_{h}}+\frac{b_{t+1}^{S P}}{1-\delta_{h}}
$$

When the subsidy rate on the balanced growth path is known, $\lim _{t \rightarrow \infty} s_{t+1}=s^{*}$ (as given in the equation (34) in Proposition 3), the initial value to be given to the subsidy rate can be obtained using (36)

$$
s_{0}=\frac{s^{*}-\lim _{t \rightarrow \infty}\left[\sum_{j=1}^{t+1}\left(\frac{b_{j}^{S P}}{1-\delta_{h}} \prod_{i=j+1}^{t+1} \frac{a_{i}^{S P}}{1-\delta_{h}}\right)\right]}{\lim _{t \rightarrow \infty}\left(\prod_{j=1}^{t+1} \frac{a_{j}^{S P}}{1-\delta_{h}}\right)} .
$$


In order to obtain the optimal path for subsidies $\left\{s_{t}\right\}_{t=0}^{\infty}$, we then use $(27)$.

For the sake of simplicity, we do not include consumption taxes in the model economy's tax system. The first best policy is not unique under a complete tax system with consumption, labor income and capital income taxes. On one hand, consumption taxes would increase the price of the consumption good and therefore distort the intratemporal first order condition. Optimal consumption taxes and labor income taxes should be of equal size and opposite sign to attain the optimal wedge mentioned above. On the other hand, time varying consumption taxes would distort the intertemporal consumption decision. Under the first best policy, capital income tax and the growth rate of consumption tax should be related in a way that the intertemporal condition in the social planner's problem is undistorted. In any case, the capital income tax should converge to zero in the long run, and consequently the consumption tax rate should converge to a constant. Chari and Kehoe (1999) discuss alternative policies that decentralize the first best allocation under different theoretical setups.

We find a unique closed-form solution for the optimal policy when we assume CobbDouglas production function, logarithmic preferences and full depreciation of physical and human capital. The following proposition presents the result.

Proposition 4 When we assume a Cobb-Douglas functional form for the production technology, i.e. $F\left(k_{t}, u_{t} h_{t}\right)=A k_{t}^{\alpha}\left(u_{t} h_{t}\right)^{1-\alpha}$, a logarithmic utility, i.e. $U\left(c_{t}, l_{t}\right)=\ln c_{t}+b \ln l_{t}$, where $b$ is the preference parameter, and total depreciation of both capitals, i.e. $\delta_{k}=\delta_{h}=$ 1 , the optimal allocation of time to working is

$$
u_{t}^{S P}=u^{S P}=\frac{(1-\alpha)(1-\beta)}{b(1-\alpha \beta)(1-\beta)+(1-\alpha+\beta \gamma)},
$$

to leisure is

$$
l_{t}^{S P}=l^{S P}=\frac{b(1-\alpha \beta)(1-\beta)}{b(1-\alpha \beta)(1-\beta)+(1-\alpha+\beta \gamma)}
$$

and the government will achieve the optimal allocations by subsidizing the foregone earnings at the rate

$$
s_{t}=s=\frac{(1-\beta) \gamma}{1-\alpha+\gamma}
$$

The lump sum transfer to finance the subsidy is

$$
\mathbb{T}_{t}=\frac{\beta \gamma}{1-\alpha} y_{t}
$$


Proof. We begin with a guess that $\frac{k_{t+1}^{S P}}{y_{t}^{S P}}, \frac{c_{t}^{S P}}{y_{t}^{S P}}, \lambda_{t}^{S P} y_{t}^{S P}, \varepsilon_{t}^{S P} h_{t}^{S P}, u_{t}^{S P}$ and $l_{t}^{S P}$ are all constant over time. Using (17), (18)-(22) we verify the guess and obtain the following policy functions

$$
\begin{aligned}
k_{t+1}^{S P} & =\alpha \beta y_{t}^{S P}, \\
c_{t}^{S P} & =(1-\alpha \beta) y_{t}^{S P}, \\
\lambda_{t}^{S P} & =\frac{1}{(1-\alpha \beta) y_{t}^{S P}}, \\
\varepsilon_{t}^{S P} & =\frac{1-\alpha}{(1-\alpha \beta) \phi u^{S P}} \frac{1}{h_{t}^{S P}} .
\end{aligned}
$$

Using (42), equating the growth rate of human capital from (4) with the growth rate of shadow price of human capital obtained from (22) and (19) we get the expression for working time, equation (37). Joining (19) and (20) we get a relationship between working and leisure time

$$
l_{t}^{S P}=\frac{b(1-\alpha \beta)}{(1-\alpha)} u_{t}^{S P} .
$$

Combining (37) and (43) we get the expression for the time devoted to leisure, equation (38). To obtain the optimal subsidy we substitute the expressions for the working and leisure time into (32), (33) and (35). The lump sum transfer is obtained from the government budget constraint, equation (16). 


\section{Conclusions}

In this study we extend Gómez (2003) by introducing leisure into the utility function. If one allows for lump sum taxes in a model of Gomez (2003), where the utility is derived only from consumption, the optimal solution can be obtained via an infinite number of combinations of labor income tax, subsidy to foregone earnings while studying and lump sum tax which balances the government budget. However, we find that only one such solution can be applied when both consumption and leisure are valued by households. Namely, to arrive at the optimal solution in a model with consumption and leisure in the utility function, the subsidy to forgone earnings should be financed through a lump sum fee and labor income taxes should be avoided.

The differences in the results are caused by the fact that the optimizing government in our economy should act as a choice architect for both the households' working and leisure time, whereas a government with the same objectives as in Gómez (2003) only targets the choice of agents' working time. A positive labor income tax increases the relative price of consumption and would make agents substitute consumption with leisure. This distortion can only be avoided with zero labor taxes. Subsidies to foregone earnings alone give the correct incentives as they make people go more to school and cut both on leisure and working times.

As proved in other papers, there might be multiple equilibrium paths in this model economy. So, our analysis implies that the optimal level of lump sum taxes and subsidies should react to the choices of labor supply and leisure time which may differ even if countries face similar characteristics and initial conditions. Thus an optimal government policy is a reaction to particular conditions in a country and a general prescription could fail. 


\section{References}

[1] Benhabib, Jess and Perli, Roberto, 1994. Uniqueness and Indeterminacy: On the Dynamics of Endogenous Growth, Journal of Economic Theory 63, 113-142.

[2] Ben-Gad, Michael, 2003. Fiscal Policy and Indeterminacy in Models of Endogenous Growth, Journal of Economic Theory, 108, 322-344.

[3] Bethmann, Dirk, 2007. A Closed-form Solution of the Uzawa-Lucas Model of Endogenous Growth, Journal of Economics 90, 87-107.

[4] Caballé, Jordi and Santos, Manuel, 1993. On Endogenous Growth with Physical and Human Capital, Journal of Political Economy 101, 1042-1067.

[5] Chamley, Christophe, 1993. Externalities and Dynamics in Models of 'Learning or Doing', International Economic Review 34, 583-609.

[6] Chari, V.V. and Kehoe, Patrick J., 1999. Optimal Fiscal and Monetary Policy, in John B. Taylor and Michael Woodford, Eds., Handbook of Macroeconomics, Vol. 1C, Elsevier, Amsterdam.

[7] García-Castrillo, Pablo and Sanso, Marcos, 2000. Human Capital and Optimal Policy in a Lucas-Type Model, Review of Economic Dynamics 3, 757-770.

[8] Gómez, Manuel A., 2003. Optimal Fiscal Policy in the Uzawa-Lucas Model with Externalities, Economic Theory 22, 917-925.

[9] Gómez, Manuel A., 2004. Optimality of the Competitive Equilibrium in the UzawaLucas Model with Sector-specific Externalities, Economic Theory, 23, 941-948.

[10] Mulligan, Casey B. and Sala-i-Martin, Xavier, 1993. Transitional Dynamics in TwoSector Models of Endogenous Growth, The Quarterly Journal of Economics, 108, $739-73$.

[11] Ladrón-de-Guevara, Antonio, Ortigueira, Salvador and Santos, Manuel S., 1997. Equilibrium Dynamics in Two-Sector Models of Endogenous Growth, Journal of Economic Dynamics and Control 21, 115-143.

[12] Ladrón-de-Guevara, Antonio, Ortigueira, Salvador and Santos, Manuel S., 1999. A Two-Sector Model of Endogenous Growth with Leisure, Review of Economic Studies $66,609-631$. 
[13] Lucas, Robert E., Jr., 1988. On the Mechanics of Economic Development, Journal of Monetary Economics 22, 3-42.

[14] Uzawa, Hirofumi, 1965. Optimum Technical Change in an Aggregative Model of Economic Growth, International Economic Review 6, 18-31. 


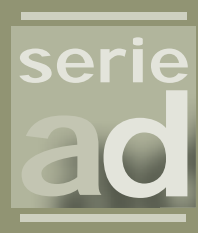

\section{I vie}

Guardia Civil, 22 - Esc. 2, 1ำ 46020 Valencia - Spain

Phone: +34 963190050

Fax: +34 963190055

\section{Department of Economics}

University of Alicante

Campus San Vicente del Raspeig

03071 Alicante - Spain

Phone: +34 965903563

Fax: +34 965903898

Website: www.ivie.es

E-mail: publicaciones@ivie.es 